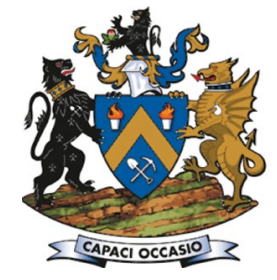

Affiliation:

${ }^{1}$ New Concept Mining,

South Africa.

Correspondence to:

B.R. Crompton

Email:

brendanc@newconceptmining.

com

\section{Dates:}

Received: 25 Jul. 2019

Revised: 14 Aug. 2019

Accepted: 30 Aug. 2019

Published: January 2020

\section{How to cite:}

Crompton, B.R. and Sheppard, J. A practical design approach for an improved resin-anchored tendon. The Southern African Insitute of Mining and Metallurgy

DOI ID:

http://dx.doi.org/10.17159/24119717/845/2020

This paper was first presented at the Deep Mining 2019 Conference, 24-25 June 2019 Misty Hills Conference Centre, Muldersdrift, Johannesburg, South Africa.

\title{
A practical design approach for an improved resin-anchored tendon
}

\author{
B.R. Crompton ${ }^{1}$ and J. Sheppard ${ }^{1}$
}

\begin{abstract}
Synopsis
The use of resin-grouted tendons is a common ground support practice in the mining industry, and various tendon designs are available. The support strength of a resin-grouted tendon is often constrained by the resin annulus between the tendon and the borehole. Effective mixing of the resin is typically achieved by ensuring the resin annulus does not exceed a specified maximum limit. Therefore, in some cases, the diameter of the tendon is dictated by the maximum allowable resin annulus and minimum diameter borehole that can be drilled and not by the support design requirements. Tendons with mastic resin capsules are prone to 'gloving' by the capsule packaging, thereby debonding the tendon from the borehole, and compromising the mixing of the resin surrounding the tendon.

This paper documents a practical investigation into the effectiveness of typical resin tendon designs in large annulus installations, and the development of an improved tendon design for such cases.
\end{abstract}

\section{Keywords}

resin, rockbolt, annulus, mixing, voids, design.

\section{Introduction}

Various designs of tendons and resin compositions are available for ground support in mining operations. In order to optimize the support design for safety and value, it is important to assess the resin and tendon as a system and not as separate elements. This paper presents a practical investigation of the effectiveness of various resin-rockbolt systems and the design of a tendon to optimize the mixing of resin during installation and maximize the strength of the installed ground support system.

This research was focused on resin bolt applications in hard rock mines with airleg rock drills, where a combination of larger support hole diameter and inconsistent resin mixing adversely affects the installation quality of resin rockbolts. The occurrence of 'gloving' in mechanized and soft rock applications has been well documented (Campbell, Mould, and MacGregor, 2004; Craig, 2012). The findings are therefore relevant to resin bolting in general.

\section{Resin annulus}

The thickness of the resin surrounding the installed tendon (see Figure 1) is a critical determinant of the support capacity of the rockbolt, as the mixing and resultant strength of the installed resin bolt is dependent on adherence to the resin annulus limits as specified by resin manufacturers (Ferreira, 2012).

Industry testing in soft rock applications has indicated that the optimal annulus range to maximize the bond strength of conventional ribbed bolts lies between $2.5 \mathrm{~mm}$ and $4.5 \mathrm{~mm}$, as illustrated in Figure 2 (Canbulat et al., 2015; Mark et al., 2003). Laboratory testing using internally threaded pipes, which approximate hard rock applications, has confirmed that the optimal annulus for resin bolting is approximately $24 \mathrm{~mm}$ (Snyman, Ferreira, and O'Connor, 2011).

South African hard rock mines commonly use $34 \mathrm{~mm}$ diameter drill bits with pneumatic rock drills when drilling support holes. Measurement of 37 holes found that the drilled hole diameters varied from $32 \mathrm{~mm}$ to $37 \mathrm{~mm}$ (see Figure 3; Crompton, 2007). Although the average support hole diameter measured was $35 \mathrm{~mm}, 30 \%$ of the measurements exceeded $36 \mathrm{~mm}$. Factors such as age and wear of the drill bit, adherence to discard criteria, condition of the rock drill, and the quality of the compressed air supply all impact on the hole diameter.

Given the recommended resin annulus range of $2 \mathrm{~mm}$ to $4 \mathrm{~mm}$ for resin bolting in both soft and hard rock applications, Table I indicates the mismatch between common diameters of rockbolts and the range of support hole diameters. 


\section{A practical design approach for an improved resin-anchored tendon}

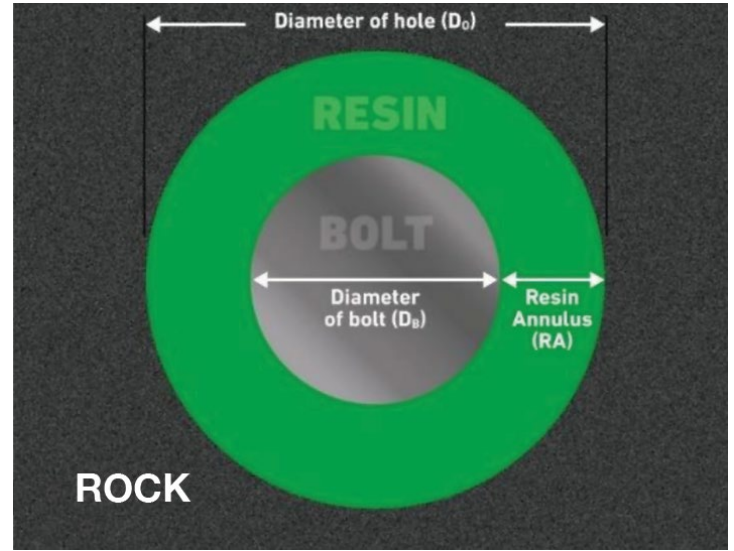

Figure 1-Definition of resin annulus

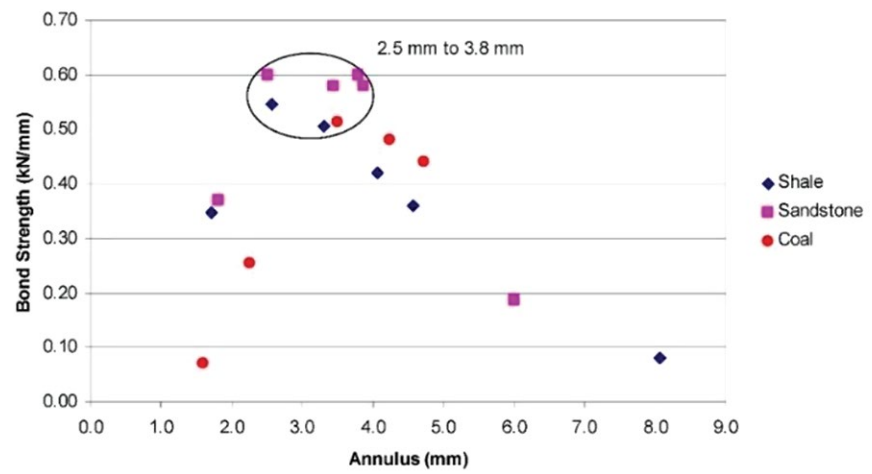

Figure 2-Effect of annulus on bond strength (Snyman, Ferreira, and O'Connor, 2011)

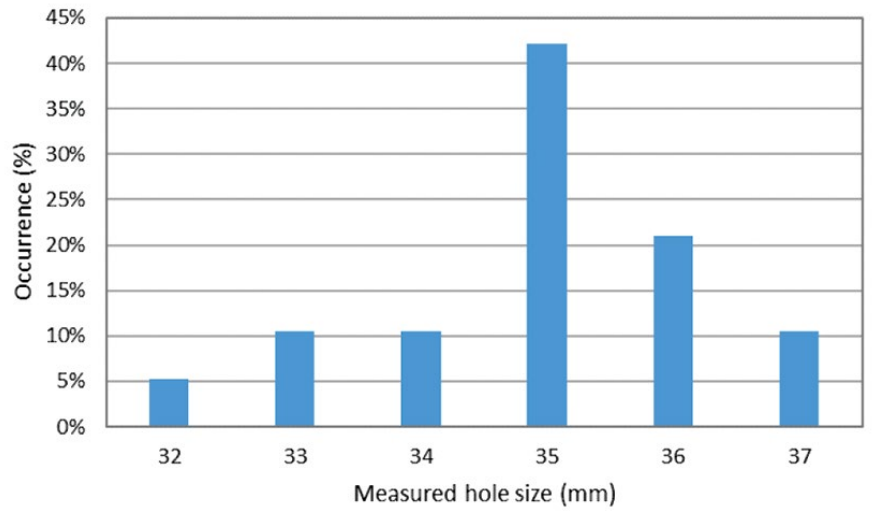

Figure 3-Support hole diameters with $34 \mathrm{~mm}$ diameter bit in hard rock (Crompton, (2007)

\begin{tabular}{|c|c|c|c|c|}
\hline \multirow[t]{2}{*}{ Bar $\varnothing(\mathrm{mm})$} & \multicolumn{4}{|c|}{ Hole diameter $(\mathrm{mm})$} \\
\hline & 32 & 34 & 36 & 38 \\
\hline 18 & 7 & 8 & 9 & 10 \\
\hline 20 & 6 & 7 & 8 & 9 \\
\hline 22 & 5 & 6 & 7 & 8 \\
\hline 25 & 3.5 & 4.5 & 5.5 & 6.5 \\
\hline
\end{tabular}

To alleviate the restrictions imposed by the resin annulus, a number of tendon designs are available with altered geometry in the anchoring portion of the tendon. This is typically achieved by the use of paddles or by increasing the diameter of the bolt.

\section{Gloving}

Gloving occurs when the plastic cartridge of the resin capsule partially or completely encases a length of the tendon during installation. Gloving is typically accompanied by poor mixing of the resin surrounding the rockbolt. Gloving is a problem common to all resin and bolt manufacturers, and occurs in all rock types, and can happen whether the resin bolt is installed with hand-held or mechanized equipment (Campbell, Mould, and MacGregor, 2004). Despite continued research into improving the effectiveness of resin bolting systems, gloving continues to be a widespread occurrence in industry (Purcel et al., 2016).

Figure 4 shows an extreme example of gloving from dynamic laboratory testing of a resin rockbolt conducted by the authors when testing a $2.4 \mathrm{~m}$ sample of a common paddle-type tendon with a $45^{\circ}$ cropped tip installed in a steel pipe.

The prevalence of gloving in resin bolt installations poses a risk in terms of the immediate support capacity of the installed rockbolts as well as the long-term corrosion protection of the steel tendons.

\section{Corrosion protection}

Corrosion of steel rockbolts can be problematic given the potential long-term exposure to corrosive conditions in some installations (Aziz et al., 2013). This is particularly noticeable in certain shafts where accelerated corrosion is evident on all steel products in use (see Figure 5).

Resin bolts can offer excellent protection from corrosion if the tendon is fully encapsulated by the cured resin. However, when the resin is compromised with voids, poor mixing, eccentric bolt

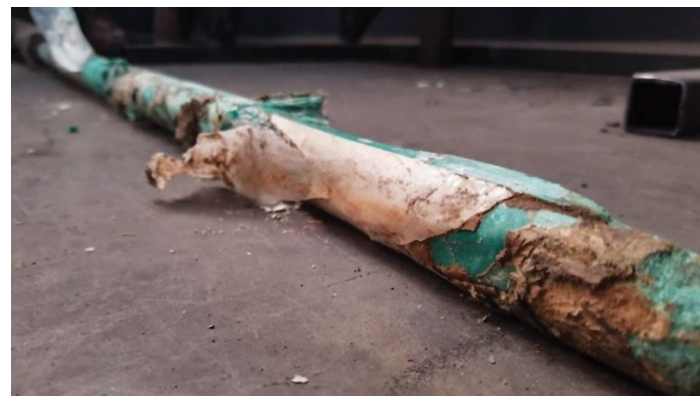

Figure 4-Gloving of common resin bolt geometry

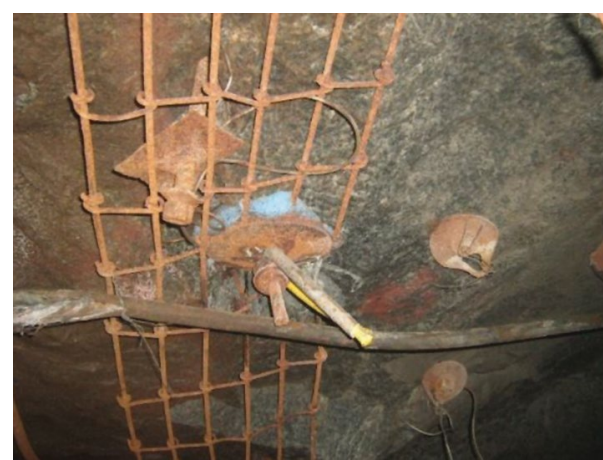

Figure 5-Visible corrosion on steel support products 


\section{A practical design approach for an improved resin-anchored tendon}

position, or cracks, the tendon can be exposed to groundwater and other corrosive media. Contact between steel and certain rock types may also result in galvanic corrosion of the steel (Chandra and Daemen, 2009). Correctly installed resin can create a barrier between the tendon and surrounding rock, preventing this, provided that the resin completely surrounds the tendon.

This paper describes the practical approach taken to further investigate the acknowledged constraints for resin bolting applications and the development of a new resin bolt design to compensate for these.

\section{Laboratory investigations}

To better understand the effect of different resin bolt designs on the quality of installed ground support, four key aspects of the performance of several tendon designs were investigated in the laboratory. Testing required the installation of a large number of resin bolt samples. In order to eliminate variability arising from inconsistencies in the installations, all samples tested were installed using an automated bolt installation machine (Figure 6). This maintained consistency during installation by automating installation factors such as rotation speed, feed speed, mixing time, and hold time.

Findings from the laboratory testing are discussed in more detail below.

\section{Centralization of resin bolts}

Centralization of a resin bolt in a support hole encourages consistent mixing of resin during installation, the even distribution of stress from the tendon into the resin annulus under tensile loading, and maximizes the corrosion protection ability of the resin by fully encapsulating the tendon. In order to assess the centralization of available bolt designs, $20 \mathrm{~mm}$ diameter paddled bolts were manufactured with $45^{\circ}$ cropped tips and also with split tips (Figure 7), and installed into steel pipes internally threaded with a resin annulus of $9 \mathrm{~mm}$.

Once the resin had cured sufficiently, samples were sliced at $50 \mathrm{~mm}$ intervals along their length so that the cross-section of the rockbolt and resin could be investigated. This helped

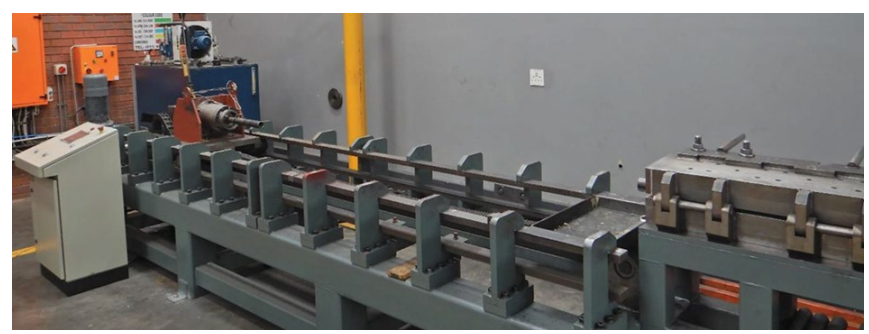

Figure 6-Automated bolt installation machine

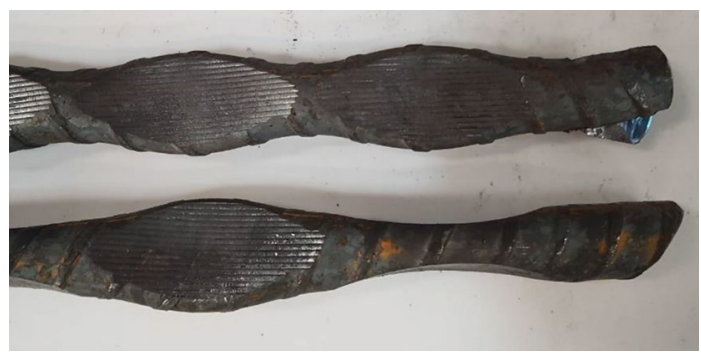

Figure $7-45^{\circ}$ tip and split tip configurations determine the degree of eccentricity for both tip designs. The tests found that neither the $45^{\circ}$ cropped tip nor the split design ensured centralization of the rockbolts during installation.

Figure 8 shows the $50 \mathrm{~mm}$ segments cut from the distal $300 \mathrm{~mm}$, the critical anchoring zone, of the resin bolts. The eccentric location of each rockbolt is sufficient to allow the bolts to contact the test pipes (and therefore the borehole walls underground) which is not desirable for corrosion protection.

Closer analysis of the test samples showed how the eccentric location of tendons within a larger diameter borehole increases the likelihood of gloving, voids, and unmixed resin (Figure 9). The large annulus to one side of the offset tendon provides a space for the resin capsule to move into without being fully shredded and mixed by the tendon.

Testing was then conducted on round and ribbed bar designs by installing samples into transparent tubes with an internal diameter of $35 \mathrm{~mm}$. The transparent tubes allowed observation of the tendon and resin during the installation and mixing process.

After installation, the samples were removed from the tubes (Figure 10) so that the installed resin bolts could be assessed for centralization, quality of mixing, gloving, and voids. Immediately noticeable were the eccentric location of each sample and a line of voids along the resin/interface on the side where the tendon contacted the tube wall. These voids resulted in an inconsistent coating of the rockbolt by the resin, with the steel being exposed in several places along the length of the sample.

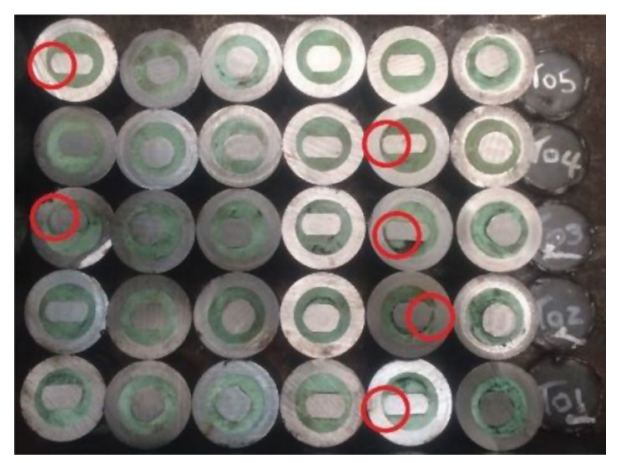

Figure 8-Eccentricity of $20 \mathrm{~mm}$ diameter paddled bar with $45^{\circ}$ tip

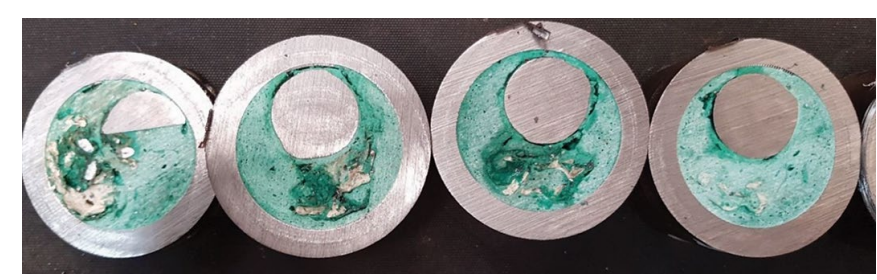

Figure 9-Poor resin mixing due to eccentric bolt location

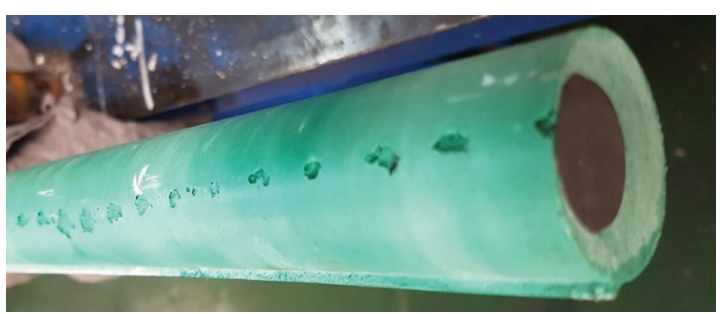

Figure 10-Eccentric location of $20 \mathrm{~mm}$ diameter ribbed bolt in $35 \mathrm{~mm}$ tube 


\section{A practical design approach for an improved resin-anchored tendon}

In practice it is almost impossible to obtain a concentric alignment of the tendon and the borehole during installation. The effect is that while the tendon is rotating around its axis (shown in red in Figure 11) it is also rotating around the axis of the borehole (shown in blue in Figure 11). During installation, the tendon constantly rotates around the perimeter of the borehole and scrapes resin off this surface.

The still frame from an installation video seen in Figure 12 illustrates this phenomenon, with the ribs of the tendon visible as a line of black marks along the length of the borehole.

Sample tendons were manufactured with a $32 \mathrm{~mm}$ tri-lobe tip on the distal end of the tendon (Figure 13). The design is intended to optimize centralization of a resin bolt in boreholes with a diameter range of $32 \mathrm{~mm}$ to $38 \mathrm{~mm}$. Samples were again installed into simulated boreholes with an internal diameter of $38 \mathrm{~mm}$ and then sliced into segments for analysis.

The tri-lobe tip design markedly improved both the centralization of the installed tendons and quality of the resin mixing.

Figure 14 provides a comparison between the tendon with a tri-lobe tip (upper row of segments) and a $45^{\circ}$ cropped tip (lower row).

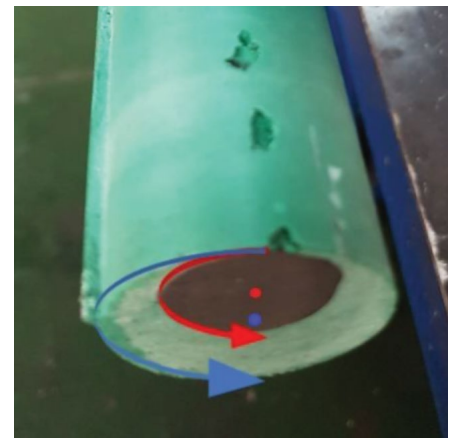

Figure 11-Eccentric location of $20 \mathrm{~mm}$ diameter ribbed bolt in $35 \mathrm{~mm}$ tube

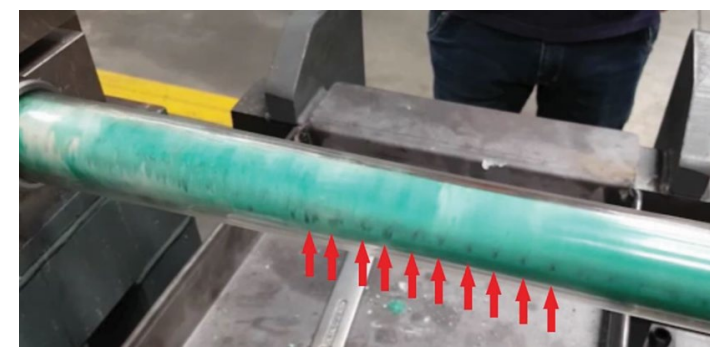

Figure 12-Scraping of resin from internal surface of the borehole

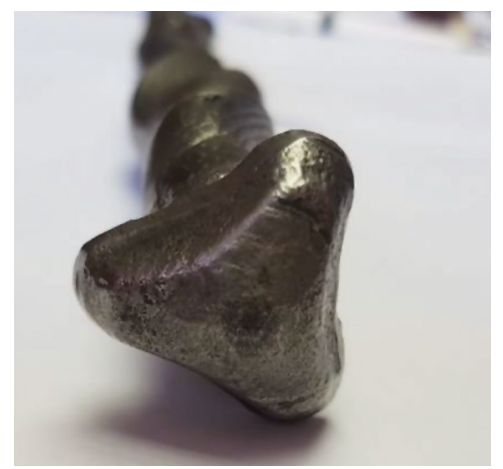

Figure 13-Tri-lobe tip design

\section{Gloving and mixing}

Gloving was prevalent in the tendons with the $45^{\circ}$ tip, with unmixed resin being noted along the entire length of the tendons. In several instances, the tendon was fully sleeved at points along the length of the anchoring zone, completely debonding the tendon from the resin in this critical region of the installed resin bolt (Figure 15).

By comparison, the tri-lobe tip design was found to pull almost all the capsule packaging to the distal end of the hole. This is done by the packaging wrapping around the very tip of the bolt as it shreds the capsule.

Figure 16 illustrates this with a side-by-side comparison of two identical tendons, with the top tendon having a tri-lobe tip and the bottom tendon a $45^{\circ}$ tip. The tendon with the tri-lobe tip has well mixed resin along the entire length of the resin bolt with the capsule packaging wrapped up at the distal end of the bolt. Conversely, the bottom tendon with the $45^{\circ}$ tip has poorly mixed resin along its length, unmixed catalyst visible, with gloving visible and unmixed resin at the distal end of the bolt.

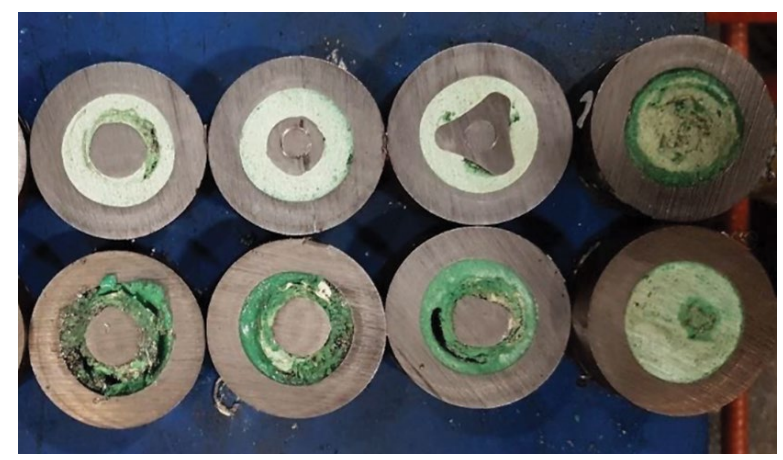

Figure $14-$ Resin mixing of tri-lobe tip (upper row) compared to $45^{\circ}$ tip

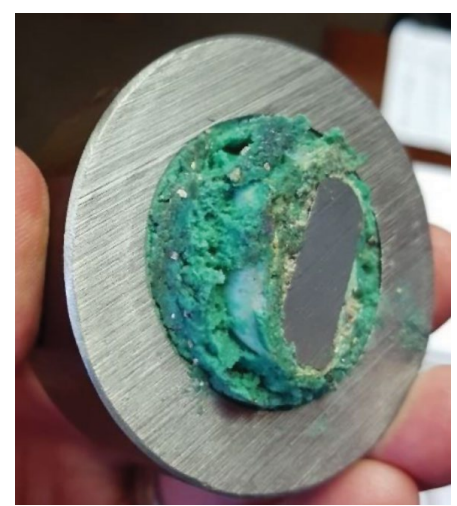

Figure $15-$ Gloving of test sample with $45^{\circ}$ tip

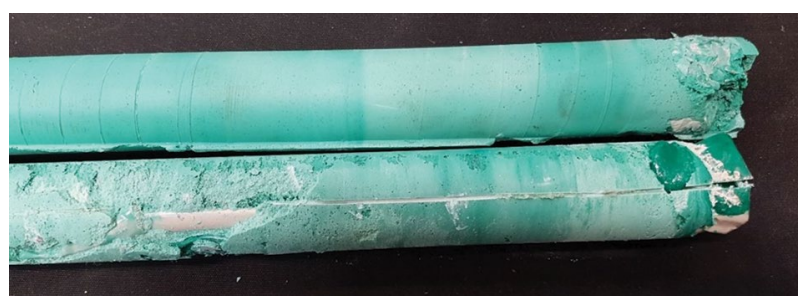

Figure $16-$ Comparison of tri-lobe tip design (top) against standard $45^{\circ}$ tip bolt 


\section{A practical design approach for an improved resin-anchored tendon}

\section{Voids in resin}

To assess the efficiency with which different tendon geometries mix resin, split paddle and flat paddle designs were tested. As anticipated, both designs improve the mixing of the resin; however, both exhibited voiding around the paddled sections of the tendons (Figure 17). These voids result from curing resin being unable to flow and fill in around the rotating paddles faces during mixing. Although acceptable load capacity was still achieved when pull-testing these samples, the presence of voids may compromise the corrosion protection of the resin bolt.

To overcome the problem of voids arising from pure rotation of the resin during mixing, a design was then tested with the paddles on the bolt twisted on the bolt axis. During mixing the rotating paddles act like an auger (Figure 18), pumping the resin towards the distal end of the borehole and preventing the formation of voids behind the rotating paddles, as can be seen in Figure 19.

\section{Load testing}

Laboratory short encapsulation pull tests

At each stage of testing, short encapsulation pull tests (SEPTs)

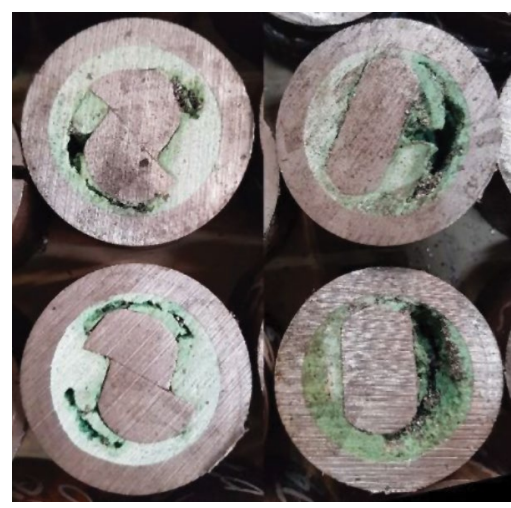

Figure 17-Voiding around flat and split paddle designs

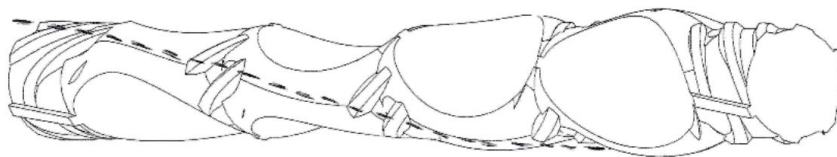

Figure 18-Voiding around flat and split paddle designs

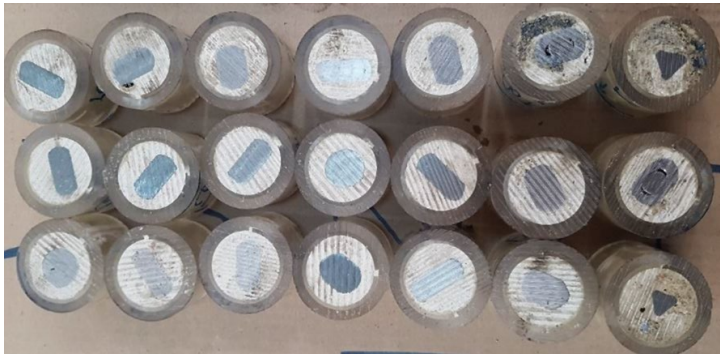

Figure 19-Good resin fill with augured paddle desig

were conducted in the laboratory to quantify the change in the bond strength arising from each design iteration, thus allowing the performance of the rockbolt to be incrementally improved with each modification. All tests were conducted in $38 \mathrm{~mm}$ diameter boreholes with an embedment length of $250 \mathrm{~mm}$, including the tip of the tendon.

As illustrated by the performance envelopes (Figure 20), the tendon design developed through the iterative development and testing appears to provide a more consistent and stiffer anchorage at $100 \mathrm{kN}$ through a combination of improved resin mixing and the tri-lobe tip compared to a conventional ribbed bar with cropped tip.

External third-party short encapsulation testing was conducted on the $20 \mathrm{~mm}$ diameter configuration of the tendon design with four different resins installed into $38 \mathrm{~mm}$ boreholes. Ten HelixBolt samples were tested with each resin and the results show that the tendon design provides similar support capacity with all four resins up to $110 \mathrm{kN}$. Performance remained consistent for three of the resins to $180 \mathrm{kN}$ (Bierman, 2018). Figure 21 is an overlay of the performance envelopes for the tendon with the four different resin types.

A higher resin bond stiffness is desirable in rockbolting as this prevents the opening of joints or fractures in the rock mass (Pariseau, 2007). Laboratory testing of 16, 18, and $20 \mathrm{~mm}$ diameter variants of the design showed that the stiffness of the resin-anchored rockbolt installed in a $38 \mathrm{~mm}$ hole is similar for all diameters when loaded up to $140 \mathrm{kN}$ (Figure 22). The $16 \mathrm{~mm}$ bolt exhibited the lowest stiffness, as expected; however, the 18 $\mathrm{mm}$ bolts appeared to be slightly stiffer than the $20 \mathrm{~mm}$ bolts. This discrepancy is believed to be a result of test variability rather than bolt performance

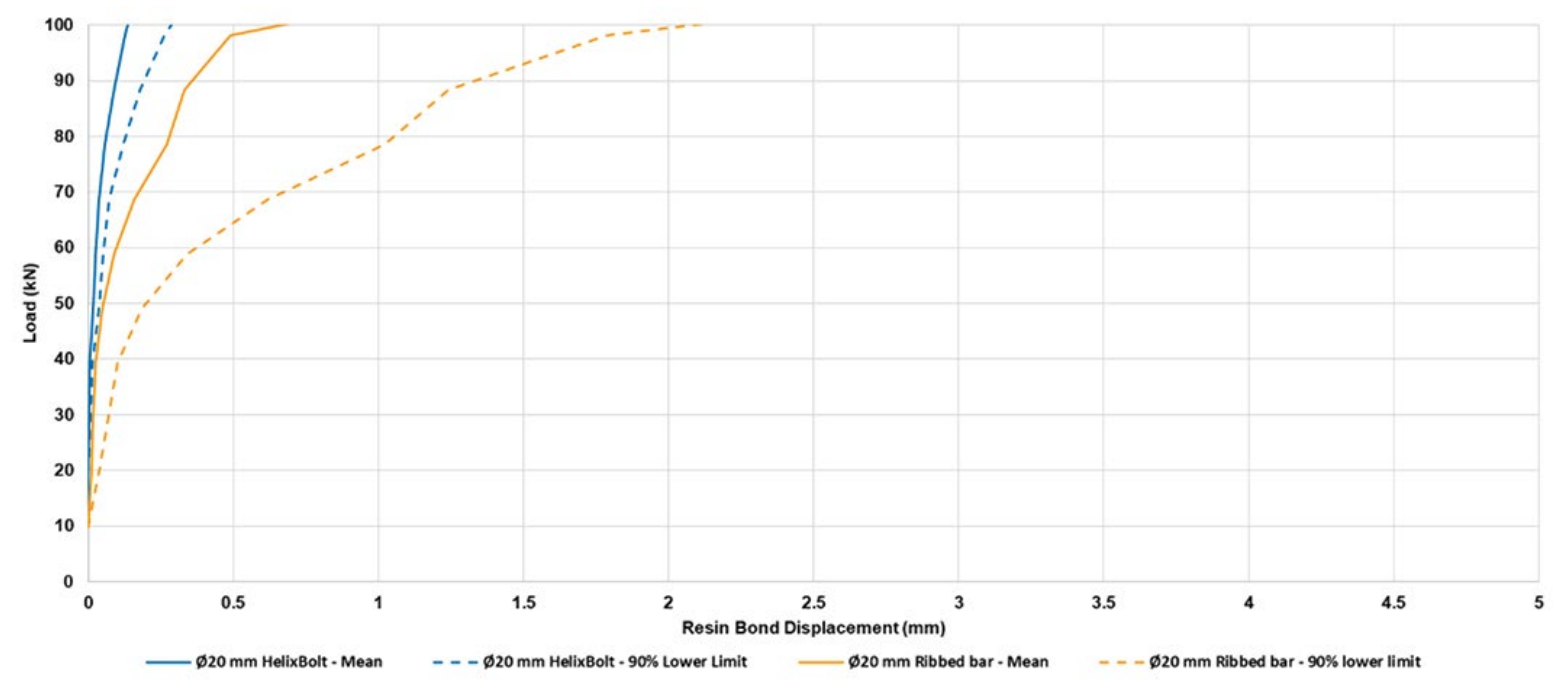

Figure 20-Laboratory SEPT results for $20 \mathrm{~mm}$ diameter standard resin bolt and HelixBolt in a $38 \mathrm{~mm}$ boreholes 


\section{A practical design approach for an improved resin-anchored tendon}

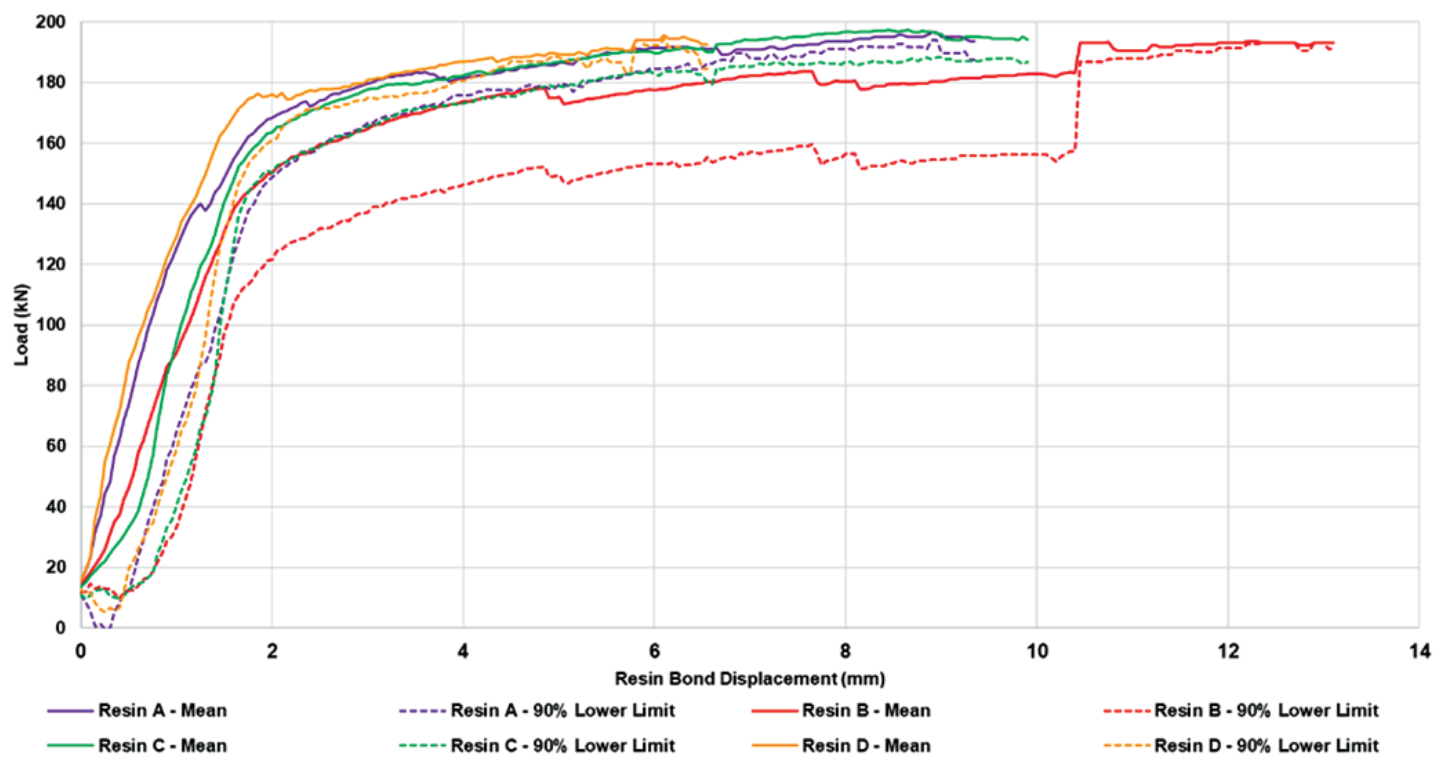

Figure 21-Laboratory SEPT results for $20 \mathrm{~mm}$ diameter HelixBolt with different resins in $38 \mathrm{~mm}$ boreholes

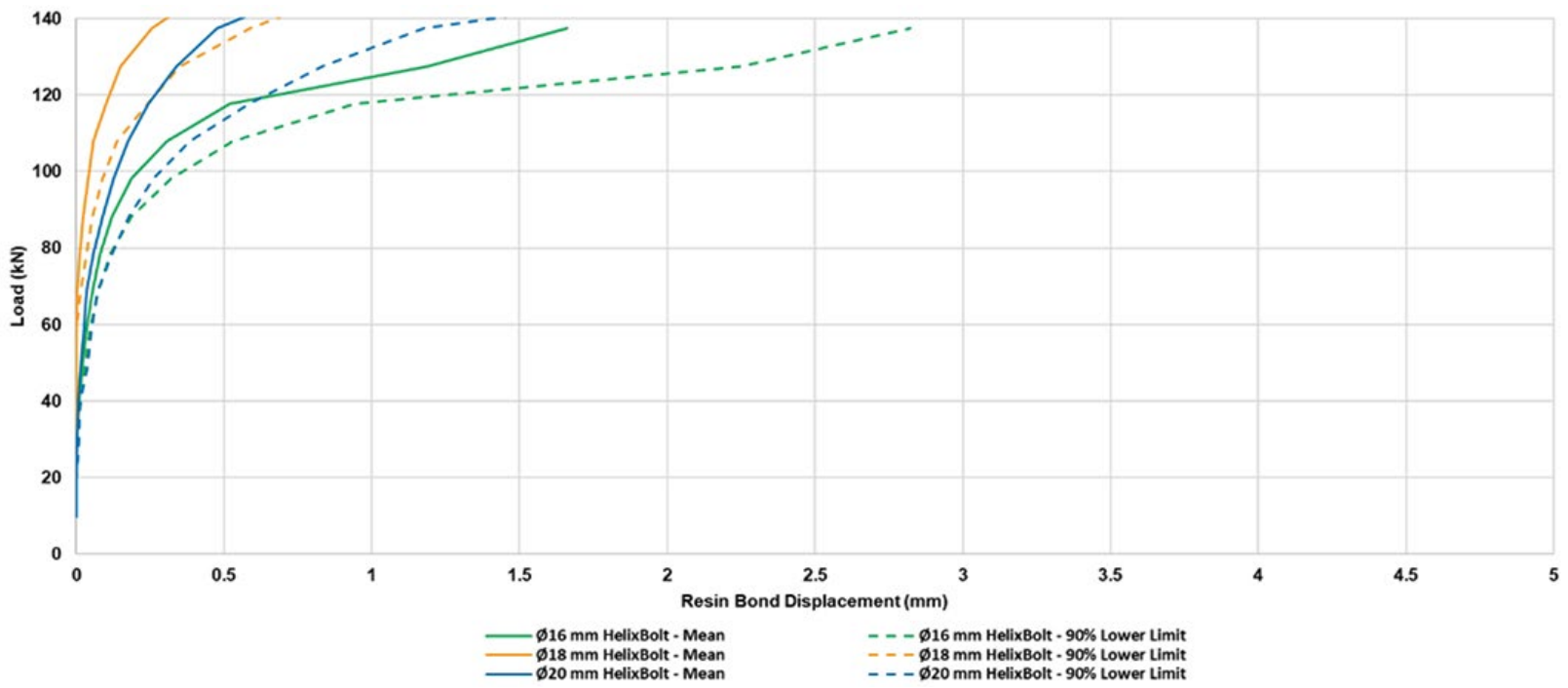

Figure 22-Laboratory SEPT results for different diameter HelixBolts in $38 \mathrm{~mm}$ holes

The authors attribute the consistent resin bond stiffness to the consistent geometry of the tri-lobe tip for all bolt diameters.

\section{Underground short encapsulation pull tests}

Subsequent to laboratory testing, underground short encapsulation testing was conducted to corroborate the laboratory results. These tests comprised five $16 \mathrm{~mm}$, five $18 \mathrm{~mm}$, and three $20 \mathrm{~mm}$ diameter samples. The rockbolts were installed into holes that ranged in measured diameter from 34.4 to $35.2 \mathrm{~mm}$ using a pneumatic rock drill mounted on an airleg to insert the bolts and mix the resin. The underground test results were corrected to account for stretch in the unbonded length of steel under load, and the performance envelopes derived from the results are presented in Figure 23. Note that these underground tests were terminated when the test loads reached $110 \mathrm{kN}$ for the $16 \mathrm{~mm}$ rockbolts, $140 \mathrm{kN}$ for the 18 bolts, and at $150 \mathrm{kN}$ for the $20 \mathrm{~mm}$ bolts (Janse van Vuuren, 2017).

Comparison of the laboratory and underground SEPT results (Figure 22 and Figure 23) shows that the laboratory tests yielded higher load capacity with less deflection than the underground tests. This is due to better control and repeatability of installation and testing parameters in the laboratory compared to testing underground.

\section{Conclusions}

The aim of this research was to investigate the effect on the bond strength of different tendon designs for rockbolts anchored in larger diameter boreholes with resin capsules. Benchmark testing was conducted to confirm the behaviour during installation and resultant support capacity of conventionally used resin-anchored rockbolts in large resin annulus installations. Incremental testing and modification of different tendon geometries was conducted to document what improvements to installation reliability and quality could be achieved.

Laboratory testing found that the geometry at the tip of the rockbolt should be close to, or larger than, the diameter of the resin capsule being used with the rockbolt to effectively shred the capsule packaging and reduce the risk of gloving of the installed rockbolt. 


\section{A practical design approach for an improved resin-anchored tendon}

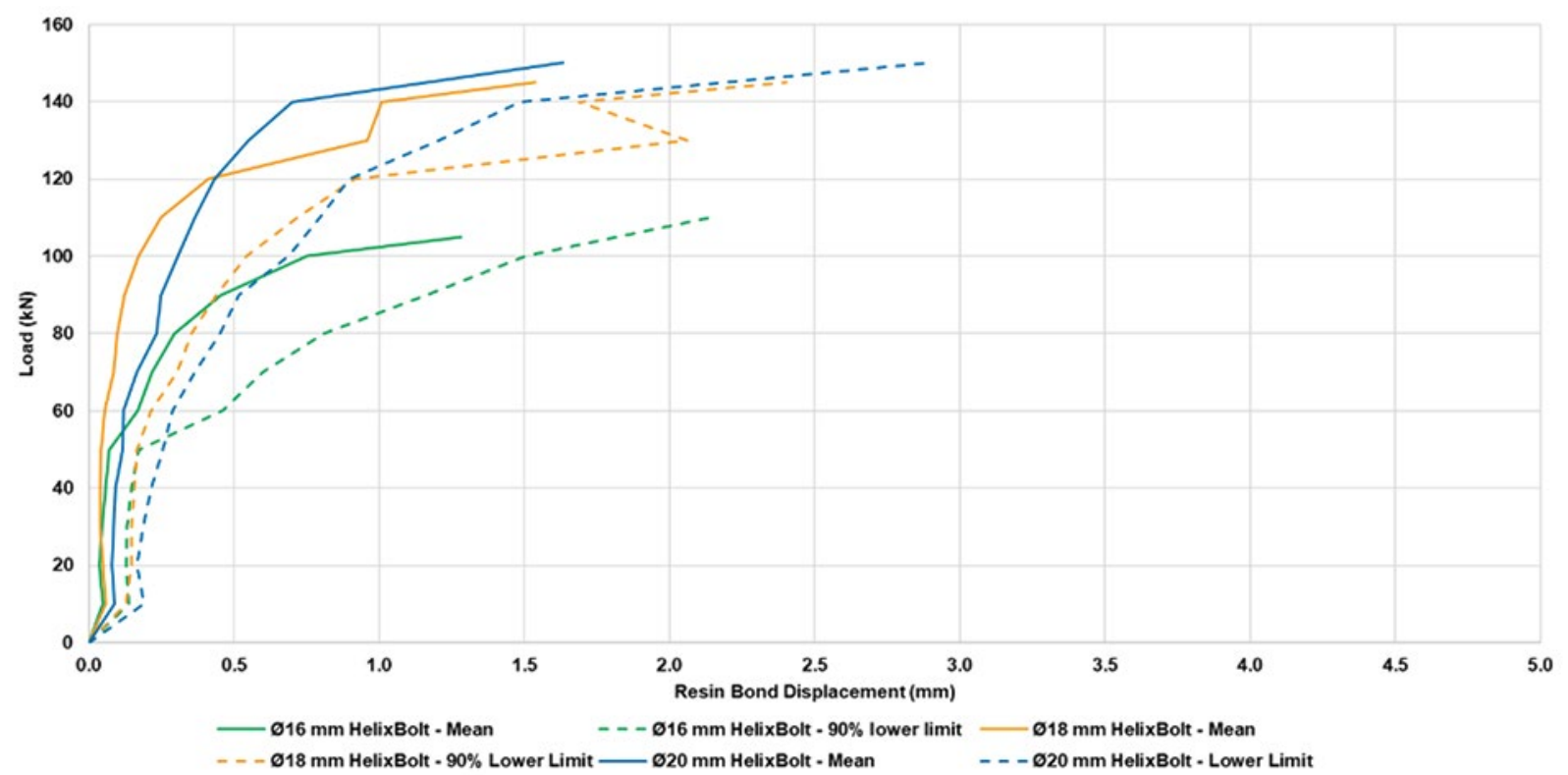

Figure 23-Normalized underground SEPT results for different diameter HelixBolts

Centralization of the rockbolt during the mixing of the resin capsule was found to be key to improving the quality of resin mixing. Non-centred rockbolts were more prone to gloving and poor mixing due to the eccentric rotation in the support hole. Rockbolts with paddle-type tendons were found to result in the best quality resin mix (once centralized). However, deformations in a rockbolt's cross-section create voids in the resin as the mixed resin is unable to flow in behind the paddles during rotation of the bar. These voids reduce the load-bearing capacity of the installed rockbolt and expose the steel to water and corrosive constituents in the host rock.

The addition of an auger, or helix, feature in the area of the rockbolt mixing the resin induces axial flow of the resin along the length of the rockbolt during rotation. This pushes the resin to the top of the hole, where anchoring is critical, and fills the voids created by the mixing geometry on the rockbolt.

The research led to a design that improved resin mixing, reduced the instance of gloving in applications with large resin annuli up to $11 \mathrm{~mm}$ (16 mm diameter bolt in $38 \mathrm{~mm}$ hole) and minimized voids in the resin annulus.

Laboratory and underground test results confirm that the derived rockbolt design can be installed in a resin bolting application with an $11 \mathrm{~mm}$ annulus and, with a $250 \mathrm{~mm}$ bond length, achieved loads in excess of $160 \mathrm{kN}$ with an $16 \mathrm{~mm}$ diameter bolt, $170 \mathrm{kN}$ with an $18 \mathrm{~mm}$ bolt, and $190 \mathrm{kN}$ with a 20 mm bolt.

\section{References}

Aziz, N., CRAIG, P., Nemcik, J., and HAI, F.I. 2013. Rock bolt corrosion - an experimental study. Proceedings of the Coal Operators, Conference 2013. University of Wollongong, Australia. pp. 144-151.

BiermAn, R. 2018. Results of laboratory testing and underground testing of NCM HelixBolt for Impala Platinum (March 2018). Groundwork Consulting (Pty), Johannesburg, South Africa. 12 pp.

CAmpbell, R., Mould, R., and MacGregor, S. 2004. Investigation into the extent and mechanisms of gloving and un-mixed resin in fully encapsulated roof bolts. Proceedings of Coal 2004: Coal Operators' Conference. Aziz, N. (ed.). University of Wollongong and Australasian Institute of Mining and Metallurgy. pp. 203-214.
Canbulat, I., Wilkinson, A., Prohaska, G., Mnisi, M., and Singh, N. 2005. An investigation into the support systems in South African collieries. Report no. CR231/0205/SIM302. Safety in Mines Research Advisory Committee, Johannesburg, South Africa.

ChandRa, D. and DaEmen, J.J. 2009. Corrosion research on rock bolts and steel sets for sub-surface reinforcement of the Yucca Mountain repository. Report no. TR-06001. University of Reno, Reno, NV.

CRAIG, P. 2012. Addressing resin loss and gloving issues at a mine with coal roof. Proceedings of the 12th Coal Operators' Conference. University of Wollongong and Australasian Institute of Mining and Metallurgy. pp. 120-128

CRompton, B. 2007. Hole survey exercise. Report no. 20070207BC. New Concept Mining, Johannesburg, South Africa.

FERREIRA, P. 2012. A perspective on underground support technologies in Southern African platinum mines to reduce safety risks and enhance productivity. Proceedings of the Fifth International Platinum Conference: 'A catalyst for change', Sun City, South Africa, 17-21 September 2012. Southern African Institute of Mining and Metallurgy, Johannesburg. pp. 445-481.

Janse van VuURen, J. 2017. Phase 2 evaluation on resin rock support tendon performance. Report no. NCM 1708-826. Saxum Mining, Johannesburg, South Africa. $23 \mathrm{pp}$

Mark, C., Compton, C.S., Dolinar, D.R., and Oyler, D.C. 2003. Field performance testing of fully grouted roof bolts. Proceedings of the 2003 SME Annual Meeting, Cincinnati. Society for Mining, Metallurgy and Exploration, Littleton, Co. pp 1-8.

Pariseau, W.G. 2007. Design Analysis in Rock Mechanics. Taylor \& Francis, London.

Purcel, J., Vandermaat, D., Callan, M., and Craig, P. 2016. Practical investigations into resin anchored roof bolting parameters. Proceedings of the 16th Coal Operators' Conference. Naj Aziz, N. and Kininmonth, B. (eds.). University of Wollongong. pp. 53-63.

Snyman, W., Ferreira, P.H., and O'Connor, D. 2011. The new generation polyester resin capsule support for rock bolt solutions to the mining industry. Proceedings of the 6th Southern African Base Metals Conference, Phalaborwa, South Africa. Southern African Institute of Mining and Metallurgy, Johannesburg. pp. 259-272. 